\title{
Essential oils composition of nine Curcuma species from Thailand: a chemotaxonomic approach
}

\author{
O. Theanphong ${ }^{1 *}$, T. Jenjittikul ${ }^{2} \&$ W. Mingvanish ${ }^{3}$ \\ ${ }^{1}$ Department of Pharmacognosy, College of Pharmacy, Rangsit University, \\ Pathumthani 12000, Thailand \\ orawan.t@rsu.ac.th \\ ${ }^{2}$ Department of Plant Science, Faculty of Science, Mahidol University, \\ Bangkok 10400, Thailand \\ ${ }^{3}$ Organic Synthesis, Electrochemistry \& Natural Product Research Unit, \\ Department of Chemistry, Faculty of Science, King Mongkut's University of Technology \\ Thonburi, Bangkok 10140, Thailand
}

\begin{abstract}
The chemical composition of the essential oils from fresh rhizomes of nine Curcuma L. species was investigated using the GC-MS technique. A total of 136 compounds, representing $97.19-99.11 \%$ of the total content of the essential oils, were identified. A dendrogram obtained from the cluster analysis based on their chemical composition was divided into two main clusters. The first cluster, with a high content of sesquiterpene hydrocarbon (e.g. $\beta$-curcumene) and oxygenated sesquiterpene (e.g. xanthorrhizol) was composed of Curcuma alismatifolia Gagnep., C. larsenii Maknoi \& Jenjitt., C. sparganiifolia Gagnep. and $C$. harmandii Gagnep. The second cluster was subdivided into two groups, IIA and IIB. Group IIA with a high content of monoterpene hydrocarbons (e.g. camphene), sesquiterpene hydrocarbons (e.g. $\alpha$-copaene), caryophyllene, and oxygenated sesquiterpenes (e.g. caryophyllene oxide), comprised Curcuma parviflora Wall. and C. rhabdota Sirirugsa \& M.F.Newman. The other, IIB, with a high content of oxygenated monoterpenes (e.g. camphor) and oxygenated sesquiterpenes (e.g. germacrone), included Curcuma rubrobracteata Škorničk. et al., C. angustifolia Roxb. and C. singularis Gagnep.
\end{abstract}

Keywords. Camphor, chemotaxonomy, ß-farnesene, xanthorrhizol

\section{Introduction}

The genus Curcuma L. in the Zingiberaceae has many species of medicinal and economic value. It comprises about 130 species distributed in South and Southeast Asia (Leong-Škorničková \& Newman, 2015). In Thailand, 46 species are now recognised (Pooma \& Suddee, 2014).

Curcuma species are perennial rhizomatous herbs with short, round to ovoid, aromatic rhizomes and starchy tuberous roots. The leaves have a linear, elliptic to ovate leaf blade, 20-200 cm long (Leong-Škorničková \& Newman, 2015). Based on the morphological characteristics of Curcuma species, i.e. anther type, the presence and absence of stylodial glands, the shape of stylodial glands when present, and bract apices, Sirirugsa et al. (2007) divided the Curcuma species of Thailand into five informal groups: Alismatifolia, Cochinchinensis, Ecomata, Longa and Petiolata. 
The rhizomes of Curcuma species have been reported as rich sources of essential oils which give them their pleasant aroma and medicinal value. Several Curcuma species have been used in ethnomedicine in many countries. For example, the rhizomes of Curcuma angustifolia Roxb. have been used in ethnomedicine in India as an antiasthmatic, antidysentery, antifungal and antipyretic (Tushar et al., 2010; Ray et al., 2011; Padal \& Sandhyasri, 2013). In Nepal, the rhizomes of Curcuma longa L. have been used as an anthelmintic while the rhizomes of $C$. amada Roxb. have been used as an antiarthritic and anti-inflammatory (Singh et al., 2012). In Bangladesh, the rhizomes of Curcuma longa have been used as an antidiarrheal and carminative (Islam et al., 2014; Khan et al., 2015). In Thailand, the rhizomes of Curcuma longa have been used to treat fevers, peptic ulcers, dyspepsia and skin diseases (Chuakul \& Boonpleng, 2003; Chuakul, 2005; Neamsuvan et al., 2012; Maneenoon et al., 2015; Tangjitman et al., 2015). In addition, the rhizomes of Curcuma sparganiifolia Gagnep. and $C$. parviflora Wall. have been used as an antiasthmatic and for wound healing, respectively (Sirirugsa, 1999; Chuakul \& Boonpleng, 2003, 2004). Furthermore, some Curcuma species, such as C. alismatifolia Gagnep., C. gracillima Gagnep., C. harmandii Gagnep., C. parviflora, C. sparganiifolia and C. thorelii Gagnep., have been cultivated for both their economic value and as ornamental plants (Larsen \& Larsen, 2006; Khamtang et al., 2014; Saensouk et al., 2016).

The chemical constituents of plants can provide characters for plant classification, the study of which has been termed chemotaxonomy (Singh, 2016). The chemical composition of the essential oils of several plants such as Pulicaria spp. (Asteraceae), Ferula spp. (Apiaceae), Ocimum spp. (Lamiaceae) and Amomum spp. (Zingiberaceae) have been utilised in their classifications (Setyawan, 2002; Kanani et al., 2011; Pirmoradi et al., 2013; Maggio et al., 2015).

However, the taxonomic usefulness of the essential oil composition from rhizomes of Curcuma species has not hitherto been reported on. Therefore, the aims of this study were to investigate the chemical composition of the essential oils from the rhizomes of nine Curcuma species and assess whether these data are useful for plant classification.

\section{Materials and methods}

\section{Plant materials}

Fresh rhizomes of nine Curcuma species were collected from different locations in Thailand (Table 1) between December 2014 and August 2017. Because of their rarity and narrow distributions, only a single fresh rhizome of each of the nine Curcuma species was collected for this initial study. All plant samples were identified by Assist. Prof. Dr Thaya Jenjittikul (Department of Plant Science, Faculty of Science, Mahidol University, Bangkok, Thailand). The voucher specimens of these plants were deposited at the College of Pharmacy, Rangsit University, Thailand. 
Table 1. Origins of the plant samples used in this study. The groups are those of Sirirugsa et al. (2007)

\begin{tabular}{lll}
\hline Plant samples & Locality & Voucher number \\
\hline Alismatifolia group & & \\
$\begin{array}{l}\text { Curcuma alismatifolia Gagnep. } \\
\text { C. } \text { harmandii Gagnep. }\end{array}$ & Prachin Buri & RSU 0042 \\
$\begin{array}{l}\text { C. } \text { larsenii Maknoi \& Jenjitt. } \\
\text { C. parviflora Wall. }\end{array}$ & Urachin Buri & RSU 0066 \\
$\begin{array}{l}\text { C. rhabdota } \text { Sirirugsa \& M.F.Newman } \\
\text { C. } \text { sparganiifolia Gagnep. }\end{array}$ & Chiang Mai & RSU 0054 \\
Longa group & Ubon Ratchathani & RSU 0052 \\
$\begin{array}{l}\text { C. } \text { angustifolia } \text { Roxb. } \\
\text { Petiolata } \text { group }\end{array}$ & RSU 0057 \\
$\begin{array}{l}\text { C. } \text { rubrobracteata } \text { Škorničk. et al. } \\
\text { Ecomata } \text { group }\end{array}$ & Chiang Mai & RSU 0063 \\
C. singularis Gagnep. & Chiang Mai & RSU 0065 \\
\hline
\end{tabular}

\section{Isolation of essential oils}

Fresh rhizomes of each plant (300 g) were washed with tap water, air dried and then blended into small pieces with a blender. The ground materials were subjected to hydro distillation using Clevenger apparatus for 3 hours. The essential oils were collected and stored at $4{ }^{\circ} \mathrm{C}$ in air-tight containers before being GC-MS analysed.

GC-MS Analysis

GC-MS analysis of nine essential oil samples was carried out on an Agilent 7890A gas chromatograph connected to a 5975C TAD inert XL EI/CI MSD. For GC-MS detection, the electron ionization system set to $70 \mathrm{eV}$ was used. They were connected to a DB-5 MS capillary column (30 $\mathrm{m} \times 0.25 \mathrm{~mm}$ i.d., and $0.25 \mathrm{~mm}$ film thickness). One microlitre of each essential oil sample diluted in ethanol (1:20 by volume) was injected into the GC-MS using a GC 80 headspace autosampler in the splitless mode. The GC injector temperature was set at $180^{\circ} \mathrm{C}$ and the GC-MSD interface temperature was set at $290^{\circ} \mathrm{C}$. The temperature programme of a $\mathrm{GC}$ oven was applied: held at $60^{\circ} \mathrm{C}$ for $1 \mathrm{~min}$, raised to $240^{\circ} \mathrm{C}$ at $3^{\circ} \mathrm{C} / \mathrm{min}$ and held isothermally at $240^{\circ} \mathrm{C}$ for $5 \mathrm{~min}$. The flow rate of the carrier gas (helium) was $1.0 \mathrm{~mL} / \mathrm{min}$. The mass spectra were scanned from 40 to $650 \mathrm{~m} / \mathrm{z}$ with a scanning rate of $2.42 \mathrm{amu} / \mathrm{second}$.

\section{Identification of essential oil components}

The chemical components of each essential oil were identified by matching their mass fragmentation pattern with NIST 05 Mass Spectral library. The amount of each compound was determined on the basis of its peak area measurement from the TIC without the use of response factors. 
Statistical analysis

All chemical compositions of more than $0.05 \%$ were considered for the statistical analysis (SPSS Statistics version 18). Hierarchical cluster analysis was done to categorise nine Curcuma species according to their essential oil composition.

\section{Results and discussion}

\section{Essential oil composition}

The rhizome essential oils obtained from hydro-distillation of nine Curcuma species were clear and pale yellow and their percentage yields are given in Table 2. The chemical components of each essential oil that was GC-MS analysed is also listed in Table 2, including the percentages of the individual components and their Kovats Indices (KIs). A total of 136 compounds, representing 97.19-99.11\% of the total oil yield, were identified. The number of chemical components found in each essential oil sample ranged from 28-60 compounds.

The rhizome essential oils of Curcuma larsenii Maknoi \& Jenjitt. (recognised here as distinct from $C$. gracillima Gagnep.) and $C$. harmandii were rich in sesquiterpenes. Xanthorrhizol [119 in Table 2] and $\beta$-curcumene [80] were the two main components in both rhizome essential oils (55.96 and 16.23\% for Curcuma larsenii and 48.99 and $25.64 \%$ for $C$. harmandii, respectively). Sesquiterpene hydrocarbons were abundant in the rhizome essential oils of Curcuma alismatifolia and C. sparganiifolia. $\beta$-Curcumene [80] was the main component in the rhizome essential oil of Curcuma alismatifolia $(42.00 \%)$ while $\alpha$-copaene [44] was the main component in the rhizome essential oil of C. sparganiifolia (21.31\%). For Curcuma rhabdota Sirirugsa \& M.F.Newman, the main composition of the rhizome essential oil was of monoterpene hydrocarbons together with sesquiterpene hydrocarbons. 3-Carene [9] (16.88\%) and $\alpha$-copaene [44] (14.84\%) were found to be the two main components in the rhizome essential oil of Curcuma rhabdota. In the rhizome essential oil of Curcuma parviflora, camphor [24] (20.48\%), camphene [4] (12.22\%), and $\alpha$-copanene [44] (11.31\%), were the three major components. The rhizome essential oils of Curcuma rubrobracteata Škorničk. et al. and $C$. angustifolia were dominated by oxygenated monoterpenes together with sesquiterpene hydrocarbons and oxygenated sesquiterpenes. Camphor [24] $(19.07 \%)$, germacrone [118] $(18.53 \%)$ and $\gamma$-elemene [50] (6.02\%) were the three major components in the rhizome essential oil of Curcuma rubrobracteata and camphor [24] (30.16\%), germacrone [118] (27.70\%) and $\alpha$-santalene [54] $(7.67 \%)$ were the three major components in the rhizome essential oil of $C$. angustifolia. For the Curcuma singularis Gagnep. rhizome, its essential oil was dominated by monoterpene hydrocarbons and oxygenated monoterpenes, which were represented by camphene [4] (13.45\%) and camphor [24] (13.27\%), respectively.

In addition, monoterpene hydrocarbons (i.e. $\alpha$-pinene [3], camphene [4], $\beta$-pinene [5] and limonene [12]), and oxygenated monoterpenes (i.e. camphor [24], borneol [27] and bornyl acetate [39]), were found in all the plant samples. 


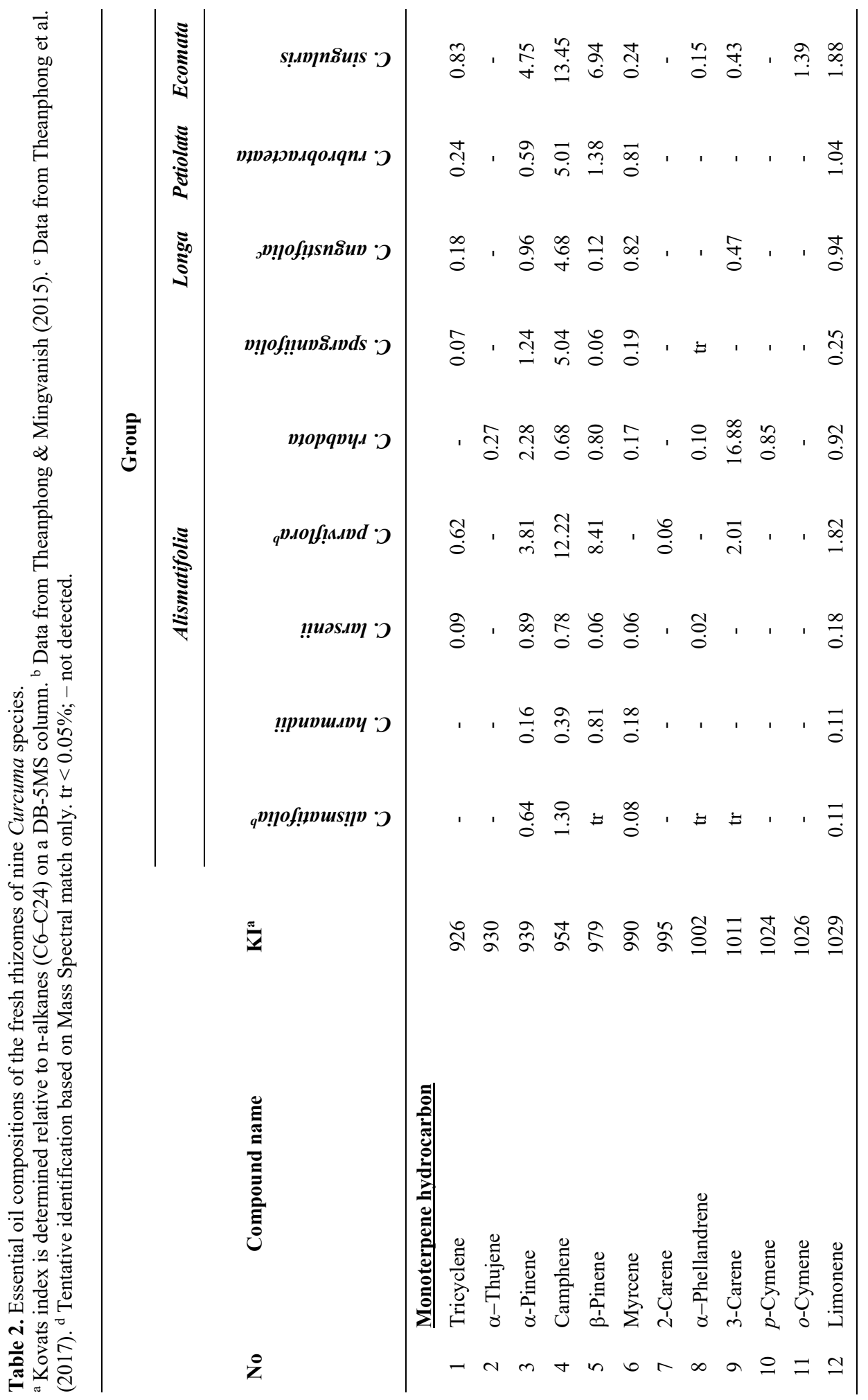




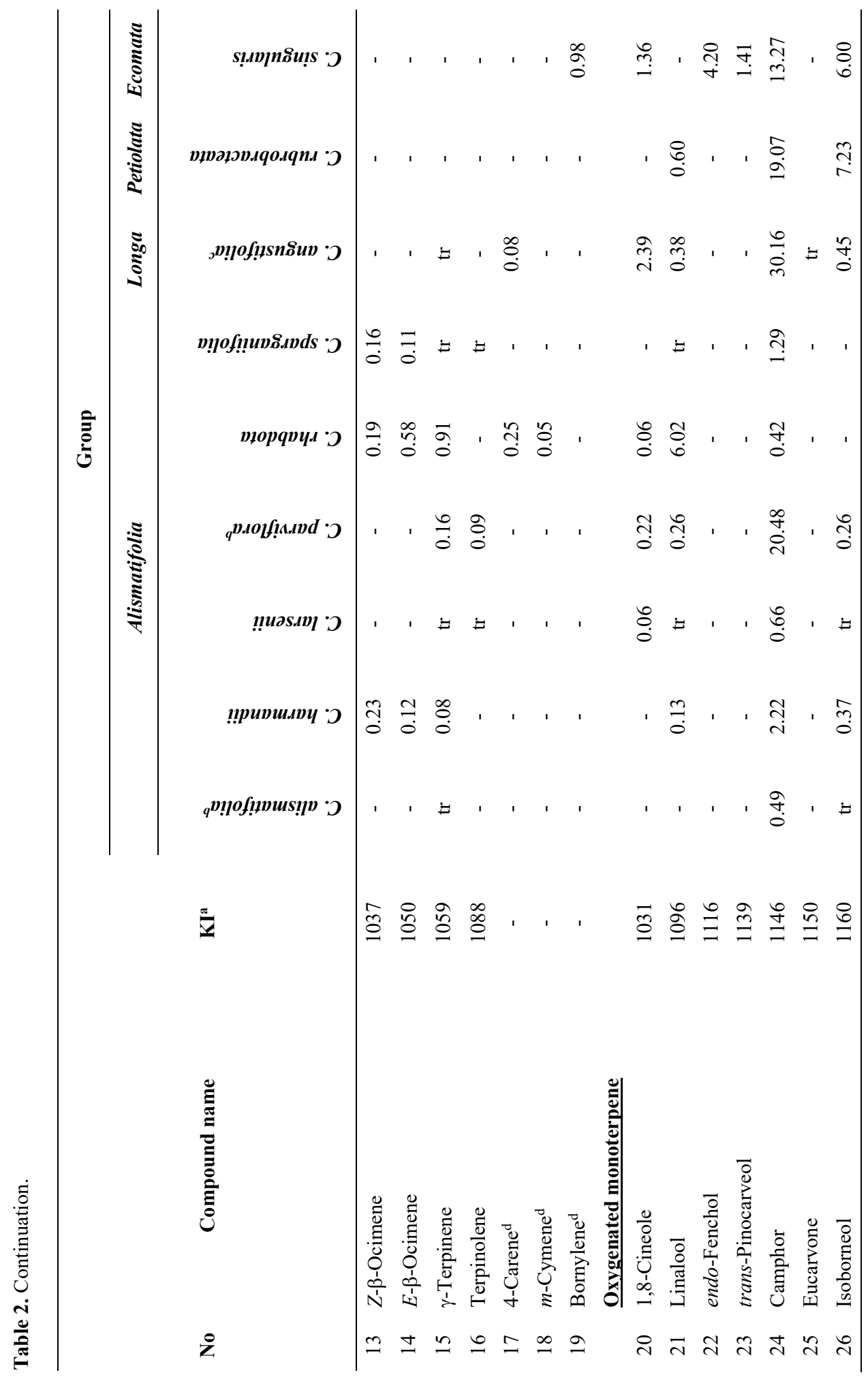




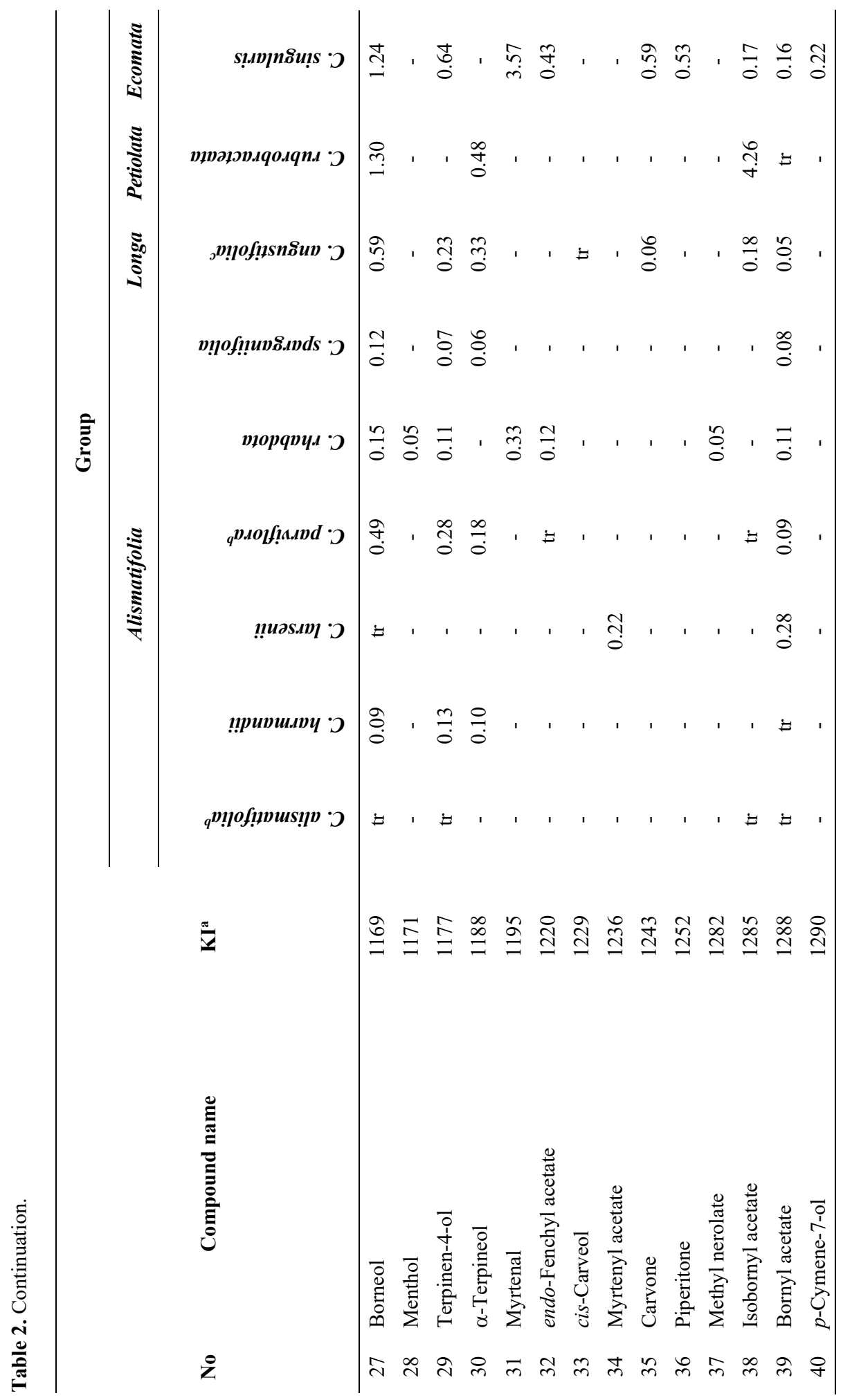




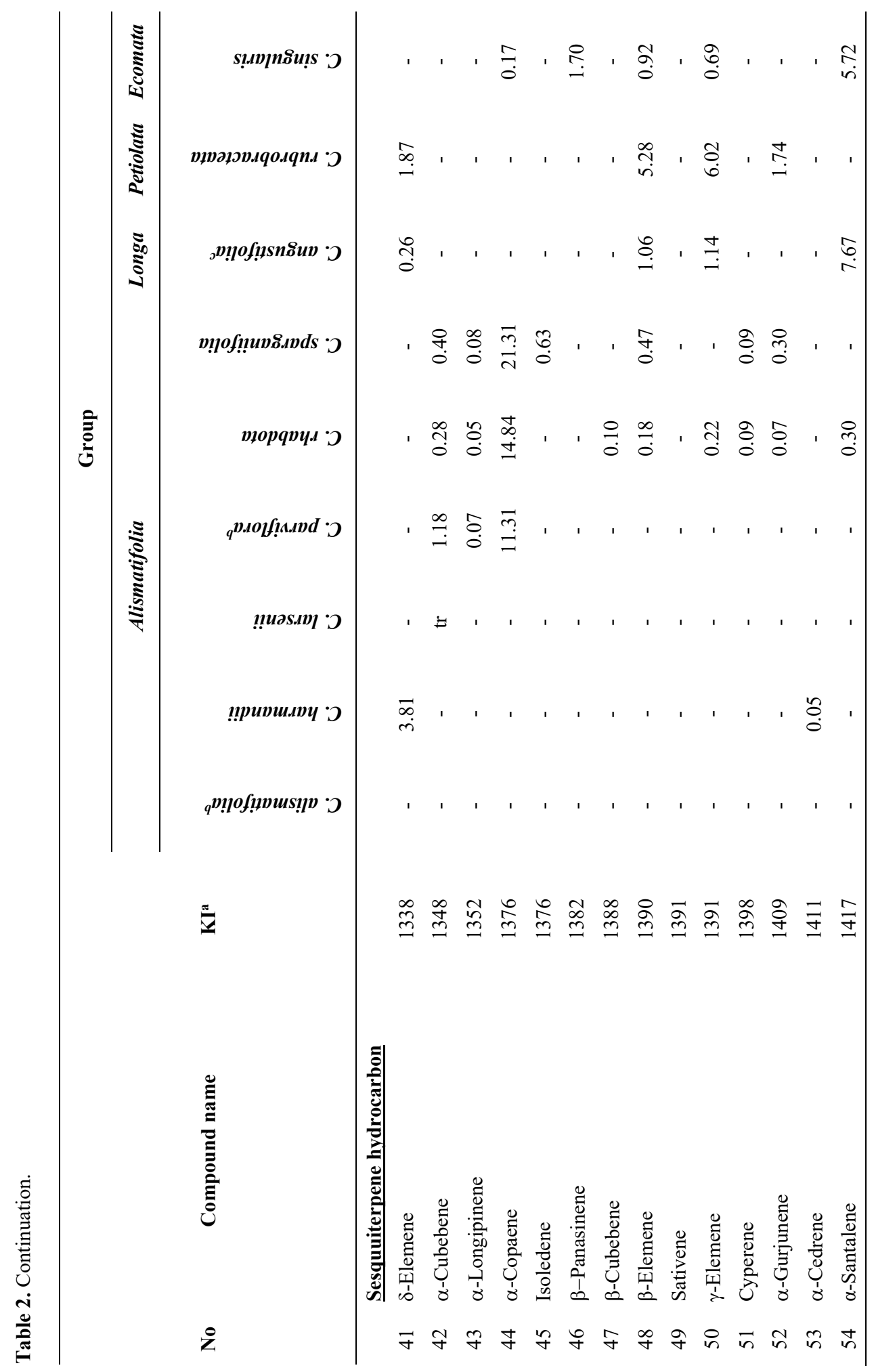




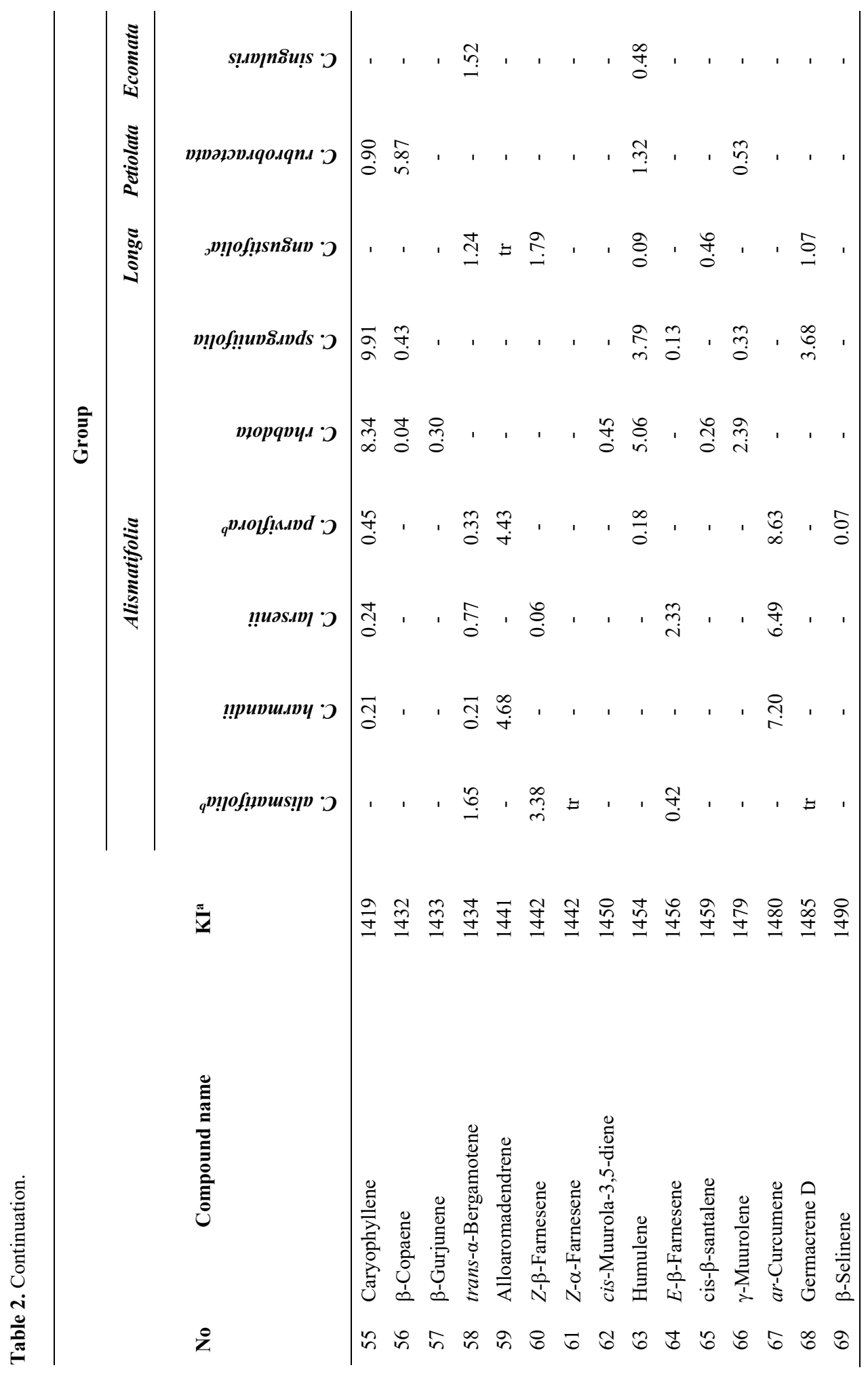




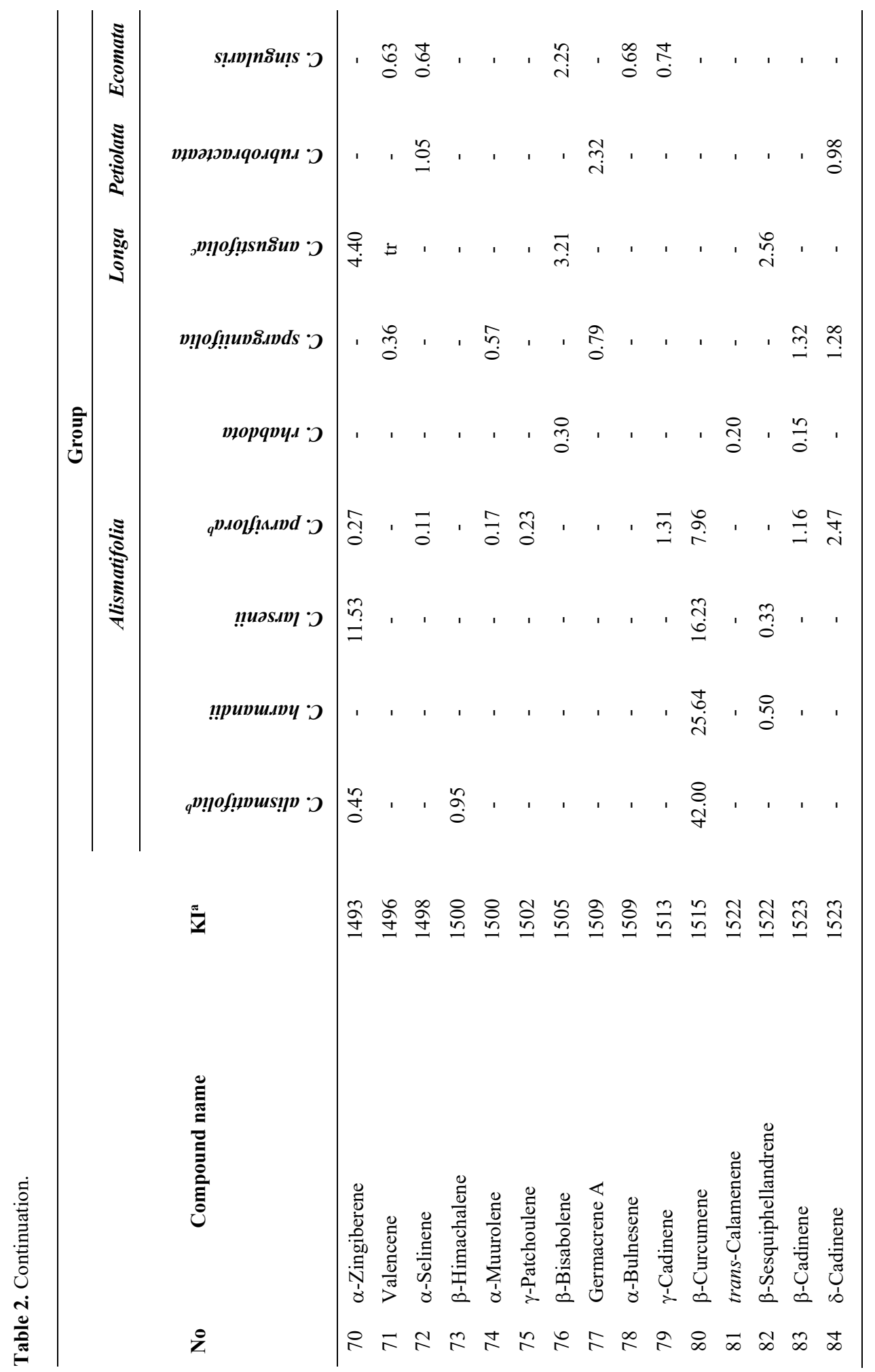




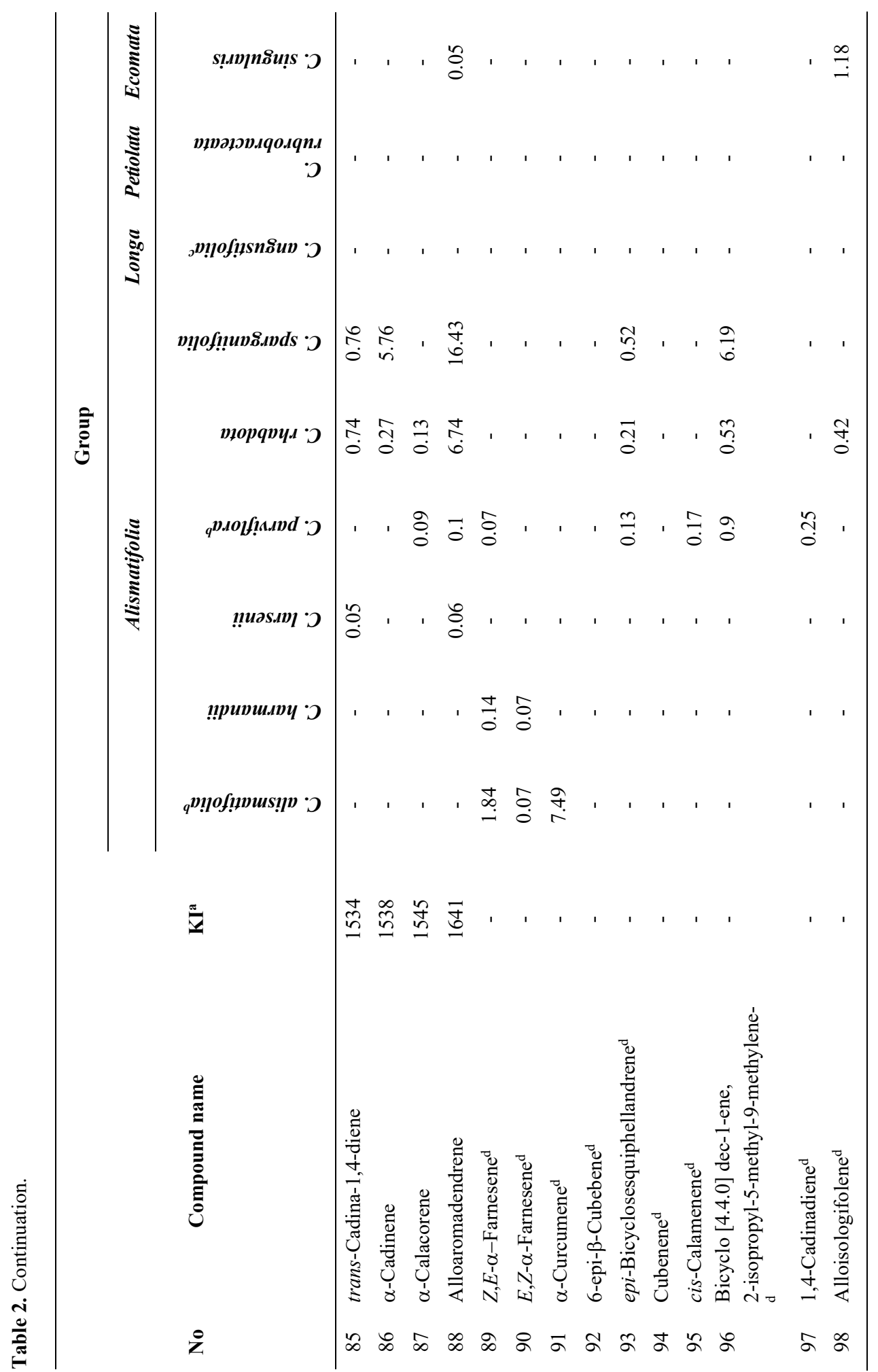




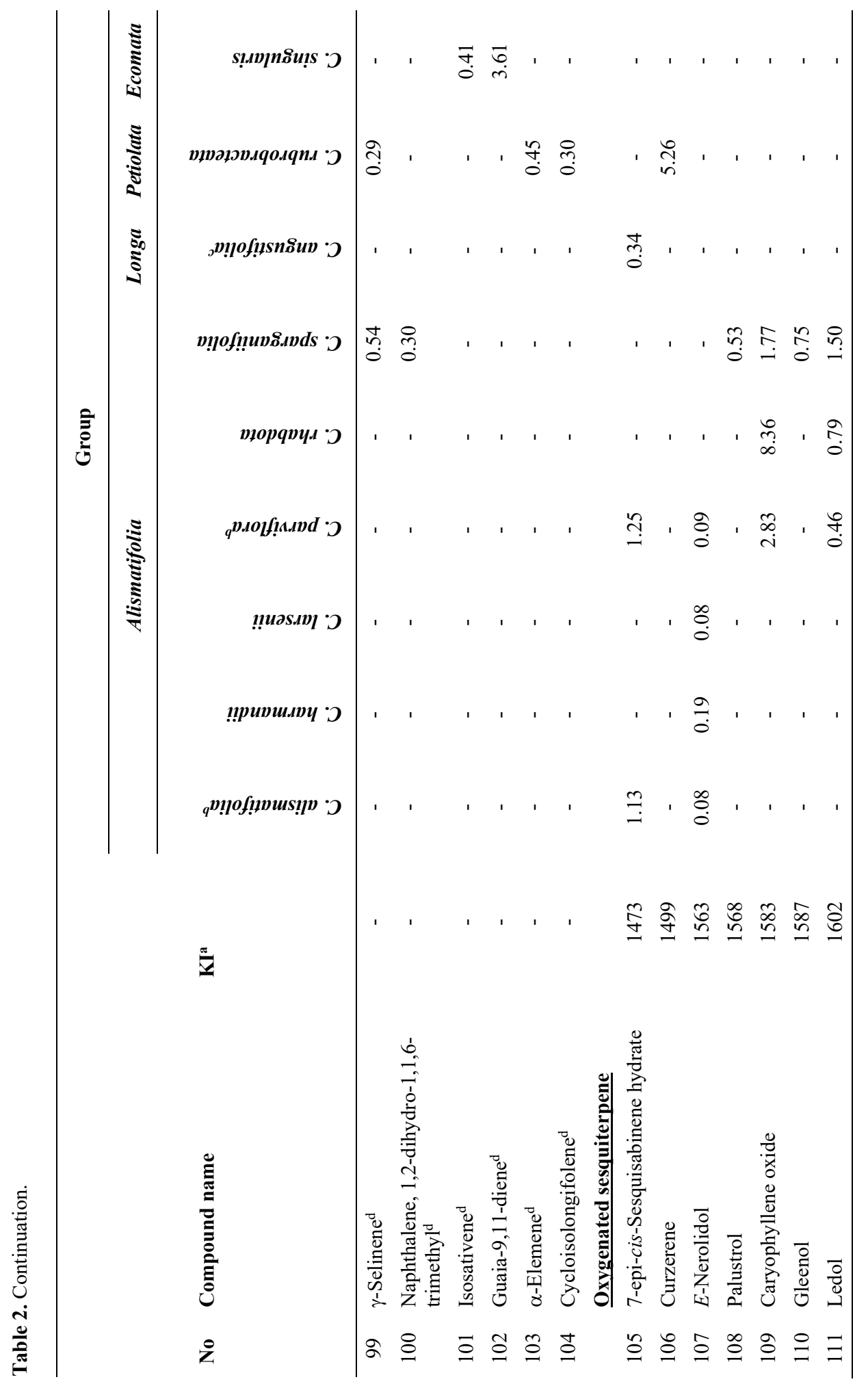




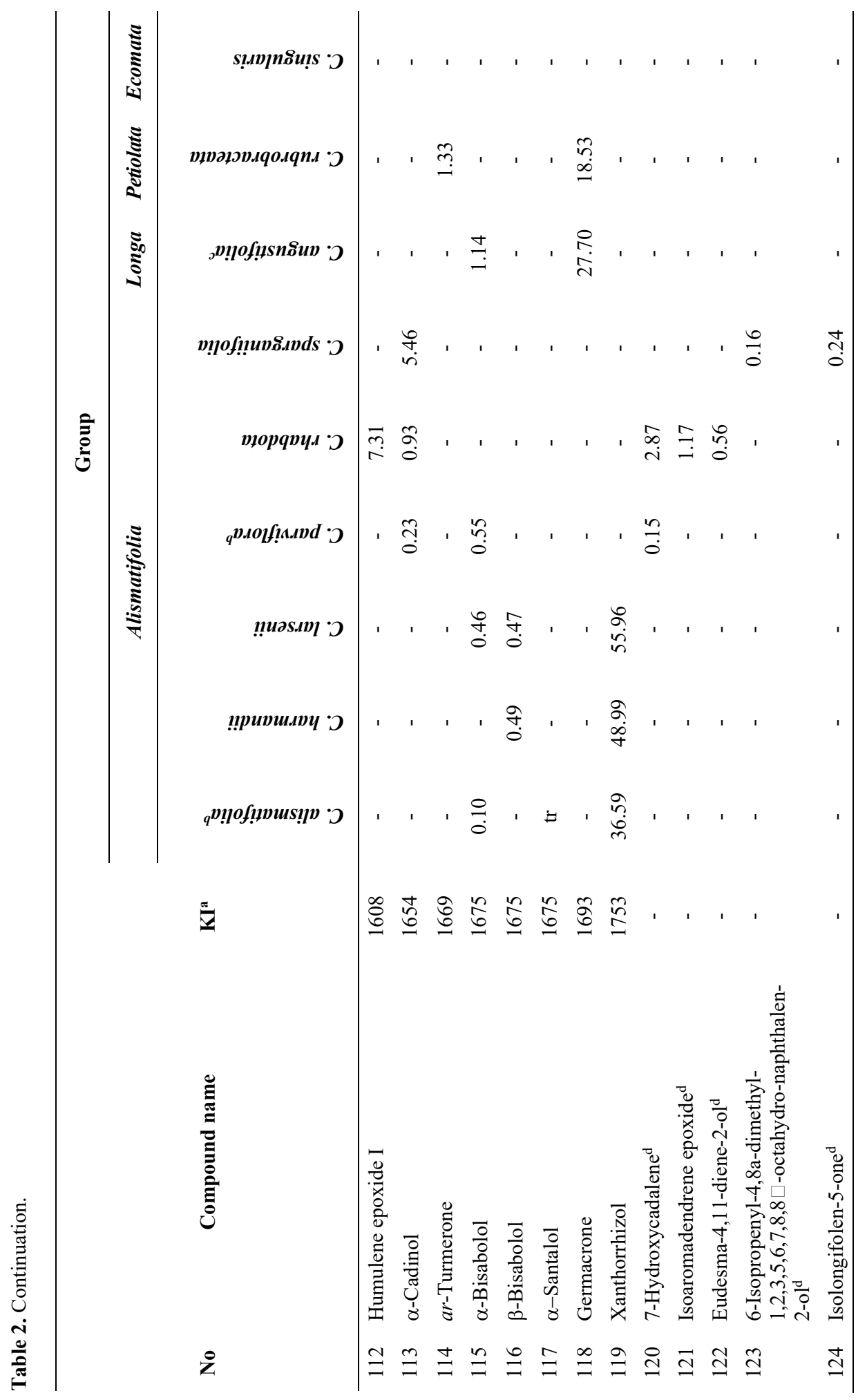




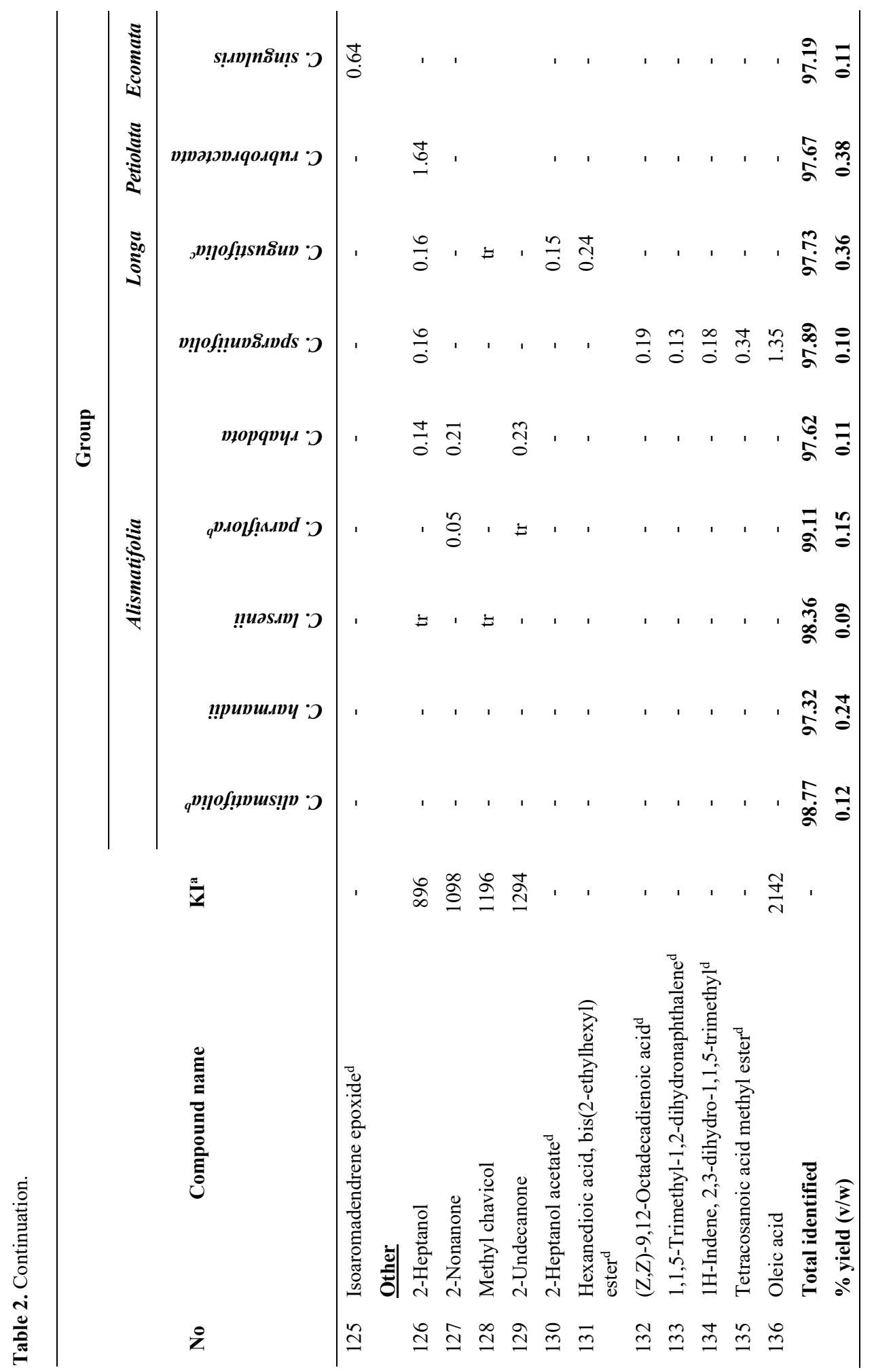


The results are in agreement with previous reports. Srivastava et al. (2006) have reported camphor and germacrone as the two main components in the rhizome essential oil of Curcuma angustifolia from Southern India. In contrast, Jena et al. (2017) reported that curzerenone, camphor and germacrone were the three major components in the rhizome essential oil of Curcuma angustifolia from India. The chemical composition of the essential oil of Curcuma singularis rhizomes was different from that reported by Cuong et al. (2017) who said that camphor was the main chemical component for Curcuma singularis from Vietnam. However, the chemical composition of essential oils might be affected by genetic factors and the environment, with chemotypes within a species and also local variabilty. In addition, the harvesting stage and extraction methods may also affect the results (Al-Reza et al., 2010; Saeb \& Gholamrezaee, 2012; Khalid \& El-Gohary, 2014; Theanphong et al., 2017).

The rhizome essential oils of Curcuma alismatifolia, $C$. harmandii and $C$. larsenii are a promising source of xanthorrhizol, which has been reported as having antioxidant, anti-inflammatory, antibacterial, neuroprotective, nephroprotective, hepatoprotective and oestrogenic properties (Hwang et al., 2000; Kim et al., 2005; Lim et al., 2005; Anggakusuma et al., 2009; Devaraj et al., 2010). In addition, the rhizome essential oils of Curcuma angustifolia, C. parviflora and C. rubrobracteata have been found to be rich in camphor. Camphor has been used as an antiseptic, analgesic, antipruritic, antitussive, nasal decongestant, expectorant, counterirritant and rubefacient (Zuccarini, 2009).

\section{Chemotaxonomic significance of essential oils from nine Curcuma species}

The dendrogram obtained from the cluster analysis based on the essential oil compositions of the fresh rhizomes of nine Curcuma species is shown in Figure 1. In the dendrogram, the nine Curcuma species are in two clusters. The first cluster includes Curcuma larsenii, C. harmandii, C. alismatifolia and C. sparganiifolia. This cluster is characterised by high levels of sesquiterpene hydrocarbons (38.99-76.38\%) and oxygenated sesquiterpenes (10.42-56.96\%), which were represented by $\beta$-curcumene [80] and xanthorrhizol [119], respectively. Curcuma larsenii and C. harmandii group together due to the presence of high levels of oxygenated sesquiterpenes represented by xanthorrhizol [119]. Curcuma alismatifolia and C. sparganiifolia separate from these due to the presence of high levels of sesquiterpene hydrocarbons represented by $\beta$-curcumene [80] and $\alpha$-copaene [44]. In addition, $\beta$-curcumene [80] is found in all plant samples in this group except Curcuma sparganiifolia while $\alpha$-copaene [44] is only found in $C$. sparganiifolia leading to this species being the most distant from the others in this group.

The second cluster is subdivided into two groups, IIA and IIB. Group IIA consists of Curcuma parviflora and C. rhabdota and is characterised by high levels of monoterpene hydrocarbons (24.97-29.20\%) and sesquiterpene hydrocarbons (42.04-42.69\%). The monoterpene hydrocarbons are primarily camphene [4] and 3 -carene [9], and the main sesquiterpene hydrocarbon is $\alpha$-copaene [44]. Curcuma rubrobracteata, $C$. angustifolia and $C$. singularis are clustered into group IIB. This cluster is characterised by high levels of oxygenated monoterpenes $(32.94-34.81 \%)$ 
and oxygenated sesquiterpenes (10.97-29.18\%). Curcuma rubrobracteata and C. angustifolia cluster together in group IIB due to the presence of high levels of oxygenated monoterpenes and oxygenated sesquiterpenes represented by camphor [24] and germacrone [118], respectively. Curcuma singularis separates from the other species in this group due to the presence of high levels of monoterpene hydrocarbons and oxygenated monoterpenes represented by camphene [4] and camphor [24], respectively. However, germacrone [118], the main oxygenated sesquiterpene in Curcuma rubrobracteata and C. angustifolia, was not found in C. singularis.

Characterised by high levels of monoterpene hydrocarbons, sesquiterpene hydrocarbons and oxygenated sesquiterpenes, the species of Clusters I and IIA are in the Alismatifolia group (Table 1). The species of Cluster IIB, Curcuma rubrobracteata, C. angustifolia and C. singularis, have been placed in the Petiolata, Longa and Ecomata groups, respectively. The presence of monoterpene hydrocarbons together with oxygenated monoterpenes might be used for differentiating the Ecomata group from the Petiolata and Longa groups. Curcuma rubrobracteata (Petiolata group) and C. angustifolia (Longa group), possess high levels of oxygenated monoterpenes and low levels of monoterpene hydrocarbons while $C$. singularis (Ecomata group) has high levels of monoterpene hydrocarbons and oxygenated monoterpenes.

Ngamriabsakul et al. (2004) reported that Curcuma alismatifolia, C. parviflora and $C$. harmandii were in the same clade based on ITS sequence data. In addition, Curcuma alismatifolia, C. parviflora, C. harmandii, C. rhabdota and C. sparganiifolia form a group based on ITS and chloroplast DNA sequence data (Zaveska et al., 2012).

On the basis of morphology, Sirirugsa et al. (2007) reported that the Longa group was more similar to the Petiolata group than to the Alismatifolia group and that the Ecomata group was the most distinct from the Alismatifolia, Longa and Petiolata groups. Our results only partially reflect the different groups as suggested by Sirirugsa et al. (2007) due to the split of the Alismatifolia group between our groups I and IIA with IIA more similar to IIB than to the rest of the Alismatifolia group. The Ecomata group was not found to be the most distinct in our results. Also, our results do not reflect the results of the molecular phylogeny which agree more closely to Sirirugsa et al. (2007).

Despite this, Singh (2016) notes that terpenoid compounds are one of the important secondary metabolites utilised for the chemotaxonomic classification of plants. For example, essential oils from several genera of Zingiberaceae, such as Amomum Roxb., Alpinia Roxb. and Zingiber Mill., have been utilised in taxonomic studies (Setyawan, 2002; Padalia et al., 2010; Theanphong et al., 2016).

\section{Conclusions}

The chemical composition of essential oils distilled from the rhizomes of nine Curcuma species was investigated using the GC-MS technique. The composition of the rhizome essential oils of Curcuma larsenii, C. rubrobracteata and C. sparganiifolia are reported for the first time. 
Distance
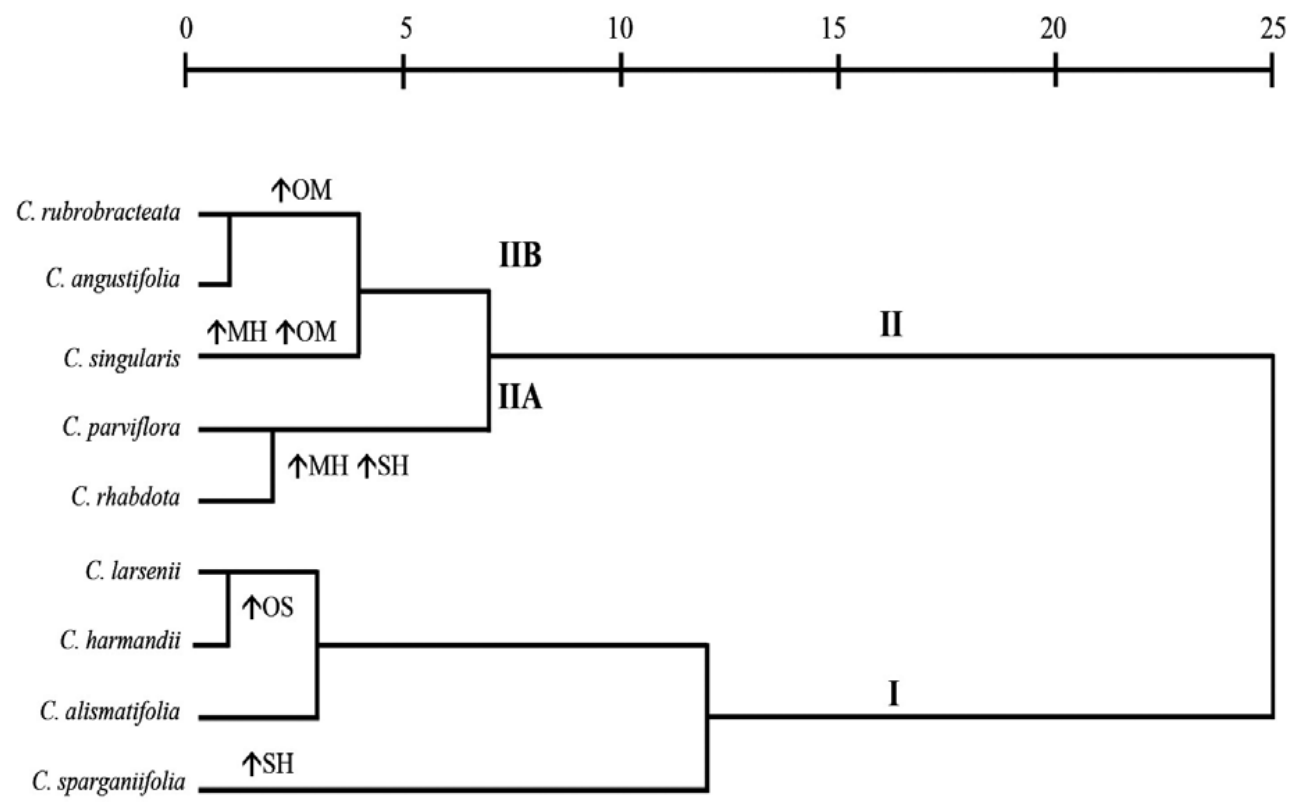

Fig. 1. A dendrogram obtained from the cluster analysis based on essential oil composition of fresh rhizomes of nine Curcuma species. MH: Monoterpene hydrocarbons; OM: Oxygenated monoterpenes; SH: Sesquiterpene hydrocarbons; OS: Oxygenated sesquiterpenes.

A dendrogram obtained from the cluster analysis shows the division of the nine Curcuma species into two clusters. The first cluster is characterised by the presence of high levels of sesquiterpene hydrocarbons and oxygenated sesquiterpenes. The second cluster is subdivided into 2 groups, IIA and IIB. Group IIA is characterised by the presence of high levels of monoterpene hydrocarbons and sesquiteterpene hydrocarbons, and group IIB is characterised by the presence of high contents of oxygenated monoterpenes. The results only partially correlate with published molecular phylogenies and morphological characteristics of the plants. The chemical composition of essential oils from rhizomes of Curcuma species can be utilised in chemotaxonomic studies with caution and after comparison to other studies.

ACKNOWLEDGEMENTS. The authors would like to acknowledge the Research Institute of Rangsit University for financial support (Grant no. 28/2559). 


\section{References}

Al-Reza, S.M., Rahman, A., Sattar, M.A., Rahman, M.O. \& Fida, H.M. (2010). Essential oil composition and antioxidant activities of Curcuma aromatica Salisb. Food Chem. Toxicol. 48(6): 1757-1760.

Anggakusuma, Yanti, Lee, M. \& Hwang, J.-K. (2009). Estrogenic activity of xanthorrhizol isolated from Curcuma xanthorrhiza Roxb. Biol. Pharm. Bull. 32(11): 1892-1897.

Chuakul, W. (2005). Medicinal plants in the Khok Pho District, Pattani Province (Thailand). Thai J. Phytopharmacy 12(2): 23-45.

Chuakul, W. \& Boonpleng, A. (2003). Ethnomedical uses of Thai Zingiberaceous plant (1). Thai J. Phytopharmacy 10(1): 33-39.

Chuakul, W. \& Boonpleng, A. (2004). Survey on medicinal plants in Ubon Ratchathani Province (Thailand). Thai J. Phytopharmacy 11(1): 33-54.

Cuong, N.M., Ha, V.T., Khanh, P.N., Van, D.T., Cuong, T.D., Huong, T.T., Thuy, D.T.T., Nhan, N.T., Hanh, N.P., Toan, T.Q. et al. (2017). Chemical compositions and antimicrobial activity of essential oil from the rhizomes of Curcuma singularis growing in Vietnam. Am. J. Essential Oils Nat. Prod. 5(4): 20-25.

Devaraj, S., Ismail, S., Ramanathan, S., Marimuthu, S. \& Fei, Y.M. (2010). Evaluation of the hepatoprotective activity of standardized ethanolic extract of Curcuma xanthorrhiza Roxb. J. Med. Plant Res. 4(23): 2512-2517.

Hwang, J., Shim, J., Baek, N. \& Pyun, Y. (2000). Xanthorrhizol: A potential antibacterial agent from Curcuma xanthorrhiza against Streptococcus mutans. Pl. Med. 66(2): 196-197.

Islam, K., Saha, S., Mahmud, I., Mohamad, K., Awang, K., Uddin, S.J., Rahman, M. \& Shilpi, J.A. (2014). An ethnobotanical study of medicinal plants used by tribal and native people of Madhupur forest area, Bangladesh. J. Ethnopharmacol. 51(2): 921-930.

Jena, S., Ray, A., Banerjee, A., Sahoo, A., Nasim, N., Sahoo, S., Kar, B., Patnaik, J., Panda, P.C. \& Nayak, S. (2017). Chemical composition and antioxidant activity of essential oil from leaves and rhizomes of Curcuma angustifolia Roxb. Nat. Prod. Res. 31(18): 2188-2191.

Kanani, M.R., Rahiminejad, M.R., Sonboli, A., Mozaffarian, V., Osaloo, S.K. \& Ebrahimi, S.N. (2011). Chemotaxonomic significance of the essential oils of 18 Ferula species (Apiaceae) from Iran. Chem. Biodivers. 8(3): 503-517.

Khalid, A.K. \& El-Gohary, A.E. (2014). Effect of seasonal variations on essential oil production and composition of Plectranthus amboinicus (Lour.) grow in Egypt. Int. Food Res. J. 21(5): 1859-1862.

Khamtang, L., Saensouk, S., Saensouk, P. \& Thanonkeo, S. (2014). Species diversity utilization of Zingiberaceae in Phu Laenkha National Park, Chaiyaphum Province. KKU Res. J. 19(6): 794-803.

Khan, A., Islam, K., Siraj, A., Saha, S., Barman, A.K., Awang, K., Rahman, M., Shilpi, J.A., Jahan, R., Islam, E. et al. (2015). Ethnomedicinal survey of various communities residing in Garo Hills of Durgapur, Bangladesh. J. Ethnobiol. Ethnomed. 11(44): 1-46.

Kim, S.H., Hong, K.O., Hwang, J.K \& Park, K.K. (2005). Xanthorrhizol has a potential to attenuate the high dose cisplatin-induced nephrotoxicity in mice. Food Chem. Toxicol. 43(1): 117-122.

Larsen, K., \& Larsen, S.S. (2006). Gingers of Thailand. Chiang Mai, Thailand: Queen Sirikit Botanic Garden, The Botanical Garden Organization, Ministry of Natural Resources and Environment. 
Leong-Škorničková, J. \& Newman, M. (2015). Gingers of Cambodia, Laos \& Vietnam. Singapore: Singapore Botanic Gardens, National Parks Board.

Lim, C.S., Jin, D.Q., Mok, H., Oh, S.J., Lee, J.U., Hwang, J.K., Ha, I. \& Han, J.S. (2005). Antioxidant and antiinflammatory activities of xanthorrhizol in hippocampal neurons and primary cultured microglia. J. Neurosci. Res. 82(6): 831-838.

Maggio, A., Riccobono, L., Spadaro, V., Campisi, P., Bruno, M. \& Senatore, F. (2015). Volatile constituents of the aerial parts of Pulicaria sicula (L.) Moris growing wild in Sicily: Chemotaxonomic volatile markers of the genus Pulicaria Gaertn. Chem. Biodivers. 12(5): 781-799.

Maneenoon, K., Khuniad, C., Teanuan, Y., Saedan, N., Prom-in, S., Rukleng, N., Kongpool, W., Pinsook, P. \& Wongwiwat, W. (2015). Ethnomedicinal plants used by traditional healers in Phatthalung Province, Peninsular Thailand. J. Ethnobiol. Ethnomed. 11(43): 1-20.

Neamsuvan, O., Tuwaemaengae, T., Bensulong, F., Asae, A. \& Mosamae, K. (2012). A survey of folk remedies for gastrointestinal tract diseases from Thailand's three southern border provinces. J. Ethnopharmacol. 144(1): 11-21.

Ngamriabsakul, C., Newman, M.F. \& Cronk, Q.C.B. (2004). The phylogeny of tribe Zingibereae (Zingiberaceae) based on its ITS (nrDNA) and trnL-F (cpDNA) sequences. Edinburgh J. Bot. 60(3): 483-507.

Padal, S.B. \& Sandhyasri, B. (2013). Ethnomedicinal investigation of medicinal plants of Sovva panchayat, Dumbriguda Mandalam, Visakhapatnam District, Andhra Pradesh. Int. J. Engin. Sci. 2(5): 55-61.

Padalia, R., Verma, R.S., Sundaresan, V. \& Chanotiya, C.S. (2010). Chemical diversity in the genus Alpinia (Zingiberaceae): comparative composition of four Alpinia species grown in Northern India. Chem. Biodivers. 7(8): 2076-2087.

Pirmoradi, M.R., Moghaddam, M. \& Farhadi, N. (2013). Chemotaxonomic analysis of the aroma compounds in essential oils of two different Ocimum basilicum L. varieties from Iran. Chem. Biodivers. 10(7): 1361-1371.

Pooma, R. \& Suddee, S. (2014). Thai plant names. Bangkok: Buddhapress.

Ray, S., Sheikh, M. \& Mishra, S. (2011). Ethnomedicinal plants used by tribals of East Nimar region, Madhya Pradesh. Indian J. Tradit. Knowl. 10(2): 367-371.

Saeb, K. \& Gholamrezaee, S. (2012). Variation of essential oil composition of Melissa officinalis L. leaves during different stages of plant growth. Asian Pacific J. Trop. Biomed. 2(2): S547-549.

Saensouk, S., Saensouk, P., Pasorn, P. \& Chantaranothai, P. (2016). Diversity and uses of Zingiberaceae in Nam Nao National Park, Chaiyaphum and Phetchabun provinces, Thailand, with a new record for Thailand. Agric. Nat. Resour. 50(6): 445-453.

Setyawan, A.D. (2002). Chemotaxonomic studies on the genus Amomum based on chemical components of volatile oils. HAYATI 9: 71-79.

Singh, A.G., Kumar, A. \& Tewari, D.D. (2012). An ethnobotanical survey of medicinal plants used in Terai forest of western Nepal. J. Ethnobiol. Ethnomed. 8(19): 1-14.

Singh, R. (2016). Chemotaxonomy: A tool for plant classification. J. Med. Plants Stud. 4(2): 90-93.

Sirirugsa, P. (1999). Thai Zingiberaceae: Species diversity and their uses. Invited lecture presented at the International Conference on Biodiversity and Bioresources: Conservation and Utilization, 23-27 Nov. 1997, Phuket, Thailand. http://www.iupac. org/symposia/proceedings/phuket97/sirirugsa.html.

Sirirugsa, P., Larsen, K. \& Maknoi, C. (2007). The genus Curcuma L. (Zingiberaceae): distribution and classification with reference to species diversity in Thailand. Gard. Bull. Singapore 59(1\&2): 203-220. 
Srivastava, A.K., Srivastava, S.K. \& Syamsundar, K.V. (2006). Volatile composition of Curcuma angustifolia Roxb. rhizome from central and southern India. Flavour Fragrance J. 21(3): 423-426.

Tangjitman, K., Wongsawad, C., Kamwong, K., Sukkho, T. \& Trisonthi, C. (2015). Ethnomedicinal plants used for digestive system disorders by the Karen of northern Thailand. J. Ethnobiol. Ethnomed. 11(27): 1-13.

Theanphong, O. \& Mingvanish, W. (2015). The rhizome volatile oils from two Thai ornamental Curcuma species. In: Proceedings of the 9th Botanical Conference of Thailand, pp. 40-48. Bangkok, Thailand.

Theanphong, O., Jenjittikul, T. \& Mingvanish, W. (2016). Chemotaxonomic study of volatile oils from rhizomes of 9 Zingiber species (Zingiberaceae). Thai J. Bot. 8(1): 127-139.

Theanphong, O., Mingvanish, W. \& Jenjittikul, T. (2017). Comparison of chemical compositions and in vitro antioxidant activities of essential oils obtained by stream distillation and water distillation from Curcuma angustifolia Roxb. roots and rhizomes from Thailand. Bull. Health Sci. Techn. 15(2): 1-14.

Tushar, Basak, S., Sarma, G.C. \& Rangan, L. (2010). Ethnomedical uses of Zingiberaceous plants of Northeast India. J. Ethnopharmacol. 132(1): 286-296.

Záveská, E., Fér, T., Šída, O., Krak, K., Marhold, K. \& Leong- Škorničková, J. (2012). Phylogeny of Curcuma (Zingiberaceae) based on plastid and nuclear sequences: Proposal of the new subgenus Ecomata. Taxon 61(4): 747-763.

Zuccarini, P. (2009). Camphor: risks and benefits of a widely used natural product. J. Appl. Sci. Environ. Managem. 13(1): 69-74. 